\title{
An Evaluation of the Nutritional Status of Persons Infected by HIVIAIDS: The Case of Ngaoundere Provincial Hospital-Cameroon Mabiama Gustave* ${ }^{* 1}$ and Mbofung Carl Mose ${ }^{2}$
}

\author{
Address: ${ }^{1}$ ENSAI, Université de Ngaoundéré, B.P. 455 Ngaoundéré-Cameroun and ${ }^{2} E N S A I$, Université de Ngaoundéré, B.P. 455 Ngaoundéré- \\ Cameroun \\ Email: Mabiama Gustave* - mabio2003@yahoo.fr; Mbofung Carl Mose - cmofung@yahoo.com \\ * Corresponding author ‡Presenting author
}

from 2005 International Meeting of The Institute of Human Virology Baltimore, USA, 29 August - 2 September 2005

Published: 8 December 2005

Retrovirology 2005, 2(Suppl I):PI29 doi:I0.I I86/I742-4690-2-SI-PI29

Morphologicals, haematologicals and biologicals alterations in the blood of persons infected by HIV-AIDS have been described by certain studies carried out in and out of Africa in AIDS patients. The objective of our study is to determine the nutritional status of an AIDS infected person in sub-Sahara in order to facilitate a proper care taking by evaluating the anthropometrical, bio-chemical (creatinin, cholesterol, transaminase), biological (red and white blood cells) perturbation parameters. It implies a study of very talking case in which 100 persons (44 men and 56 women) did participate. These persons were given questionnaires in which information on the civil, chemical states, the anthropometrical parameters and the diet of the last two days were asked. Only those of the persons who gave their accord were retained. Blood specimen was taken for HIV-AIDS screening test (Elisa and Western blot) and to dose the transaminases, cholesterol, creatinin by spectrophotometer. Both the weight and skinfold were taken using the Holtain calliper. The results of this study revealed 72 persons infected and 28 negative cases. The transaminases increased enormously $(p<0,000003)$ in the course of the infection. This increase must either be the consequence of a co-infection VIH-VHB or VIH-VHC responsable of the hepatological cytolysis or the action of opportuned infections. In PLHIV, the increase of transaminase which is two to tree times superior to the normal (p $<0,05)$ translates not only a tissue necrosis but equally reveals a steatosis, a fibrosis and a hepatic cirrhosis. HIV infection and especially the presence of signs of an opportuned infection which provokes a muscular dystrophy revealed a significant drop of the creatinemia $(p<0,05)$. The seropositive persons suffer from hypocholesterolemia which can have a serious effect on the maintenance of their health, ponderal deficit compared to the initial weight $(\mathrm{p}<0,05)$, and present a BMI and degree of skinfold which attests denutrition. The anthropometical parameters are influenced by the diet and the serological status. Some profound modifications in the composition of surrounding blood cells (leucopeania, aneamia) in the infected persons $(\mathrm{p}<0,05)$. The infected women present greater importance $(\mathrm{p}<0,05)$ of energy needs than the non-infected. Certain signs of opportuned illnesses lead to greater energy deficit than others; particularly the case of tuberculosis as a characteristic sign and cough as sign associated with HIV infection. Nutritional support needs to be given to PLHIV and, in an holistic manner, in complement of all others treatments. 